\title{
PET-BASED TREATMENT RESPONSE EVALUATION IN RECTAL CANCER: PREDICTION AND VALIDATION
}

Citation for published version (APA):

Janssen, M. H. M., Ollers, M. C., van Stiphout, R. G. P. M., Riedl, R. G., van den Bogaard, J., Buijsen, J., Lambin, P., \& Lammering, G. (2012). PET-BASED TREATMENT RESPONSE EVALUATION IN RECTAL CANCER: PREDICTION AND VALIDATION. International Journal of Radiation Oncology Biology Physics, 82(2), 871-876. https://doi.org/10.1016/j.jijrobp.2010.11.038

Document status and date:

Published: 01/02/2012

DOI:

10.1016/j.jijrobp.2010.11.038

Document Version:

Publisher's PDF, also known as Version of record

Document license:

Taverne

Please check the document version of this publication:

- A submitted manuscript is the version of the article upon submission and before peer-review. There can be important differences between the submitted version and the official published version of record.

People interested in the research are advised to contact the author for the final version of the publication, or visit the DOI to the publisher's website.

- The final author version and the galley proof are versions of the publication after peer review.

- The final published version features the final layout of the paper including the volume, issue and page numbers.

Link to publication

\footnotetext{
General rights rights.

- You may freely distribute the URL identifying the publication in the public portal. please follow below link for the End User Agreement:

www.umlib.nl/taverne-license

Take down policy

If you believe that this document breaches copyright please contact us at:

repository@maastrichtuniversity.nl

providing details and we will investigate your claim.
}

Copyright and moral rights for the publications made accessible in the public portal are retained by the authors and/or other copyright owners and it is a condition of accessing publications that users recognise and abide by the legal requirements associated with these

- Users may download and print one copy of any publication from the public portal for the purpose of private study or research.

- You may not further distribute the material or use it for any profit-making activity or commercial gain

If the publication is distributed under the terms of Article $25 \mathrm{fa}$ of the Dutch Copyright Act, indicated by the "Taverne" license above, 


\title{
PET-BASED TREATMENT RESPONSE EVALUATION IN RECTAL CANCER: PREDICTION AND VALIDATION
}

\author{
Marco H. M. Janssen, M.Sc., ${ }^{*}$ Michel C. Öllers, M.Sc., Ph.D., ${ }^{*}$ \\ Ruud G. P. M. van Stiphout, M.Sc., ${ }^{*}$ Robert G. Riedl, M.D., ${ }^{\dagger}$ JøgGen van den Bogaard, M.A., * \\ Jeroen Buijsen, M.D., ${ }^{*}$ PhilipPe Lambin, M.D., Ph.D., ${ }^{\ddagger}$ and Guido Lammering, M.D., Ph.D. ${ }^{\ddagger}$ \\ *Department of Radiation Oncology (MAASTRO), GROW Research Institute, University Medical Centre Maastricht, Maastricht, the \\ Netherlands; and 'Department of Pathology, University Medical Centre Maastricht, Maastricht, the Netherlands
}

\begin{abstract}
Purpose: To develop a positron emission tomography (PET)-based response prediction model to differentiate pathological responders from nonresponders. The predictive strength of the model was validated in a second patient group, treated and imaged identical to the patients on which the predictive model was based.

Methods and Materials: Fifty-one rectal cancer patients were prospectively included in this study. All patients underwent fluorodeoxyglucose (FDG) PET-computed tomography (CT) imaging both before the start of chemoradiotherapy (CRT) and after 2 weeks of treatment. Preoperative treatment with CRT was followed by a total mesorectal excision. From the resected specimen, the tumor regression grade (TRG) was scored according to the Mandard criteria. From one patient group $(n=30)$, the metabolic treatment response was correlated with the pathological treatment response, resulting in a receiver operating characteristic (ROC) curve based cutoff value for the reduction of maximum standardized uptake value $\left(S V_{\text {max }}\right)$ within the tumor to differentiate pathological responders (TRG 1-2) from nonresponders (TRG 3-5). The applicability of the selected cutoff value for new patients was validated in a second patient group $(n=21)$.

Results: When correlating the metabolic and pathological treatment response for the first patient group using $\overline{R O C}$ curve analysis (area under the curve $=0.98$ ), a cutoff value of $48 \% \mathrm{SUV}_{\max }$ reduction was selected to differentiate pathological responders from nonresponders (specificity of $100 \%$, sensitivity of $64 \%$ ). Applying this cutoff value to the second patient group resulted in a specificity and sensitivity of, respectively, $93 \%$ and $83 \%$, with only one of the pathological nonresponders being false positively predicted as pathological responding.

Conclusions: For rectal cancer, an accurate PET-based prediction of the pathological treatment response is feasible already after 2 weeks of CRT. The presented predictive model could be used to select patients to be considered for less invasive surgical interventions or even a "wait and see" policy. Also, based on the predicted response, early modifications of the treatment protocol are possible, which might result in an improved clinical outcome. () 2012 Elsevier Inc.
\end{abstract}

Locally advanced rectal cancer, Chemoradiotherapy, Sequential PET-CT imaging, Pathological response prediction, TRG.

\section{INTRODUCTION}

Over the past several years, the reduction of the metabolic activity of rectal tumors during preoperative treatment, assessed with repeated positron emission tomography (PET)-computed tomography (CT) imaging, has been shown to accurately predict the pathological treatment response (114). Most of the published studies about PET-based treatment response predictions determined a (receiver operating characteristic [ROC] curve based) cutoff value, percent reduction of the mean, or maximum standardized uptake value $\left(\mathrm{SUV}_{\max }\right)$ within the tumor after finishing preoperative treatment, to differentiate pathological responders from nonresponders. However, also early metabolic treatment responses within the tumor, as early as 2 weeks after the start of preoperative treatment, were presented as a strong predictor of the pathological treatment response $(9,10,12)$. Two studies even presented early PET-based response predictions as being more accurate when compared to response predictions based
Reprint requests to: Marco H.M. Janssen, M.Sc., MAASTRO Clinic, Dr. Tanslaan 12, 6201 BN, Box 1588, Maastricht, The Netherlands. Tel: +31(0)884455779; Fax: +31(0)884455667; E-mail: marco.janssen@maastro.nl

${ }^{\ddagger}$ Equal contribution.

Conflict of interest: none.

Acknowledgments-The authors would like to thank Siemens MI for technical and financial support. We acknowledge financial sup- port from the Netherlands Organization for Health Research and Development (ZonMw; clinical fellowship awarded to G.L.). Also, we acknowledge the efforts of the pathology departments of all participating hospitals for providing us with the pathological specimens of the included patients.

Received Aug 30, 2010, and in revised form Oct 14, 2010. Accepted for publication Nov 12, 2010. 
on pre- and posttreatment PET-imaging $(9,12)$. A prediction of the pathological treatment response early during preoperative treatment is more attractive for clinical practice, because this enables individualized treatment schemes in the near future, possibly resulting in an improved tumor control or modified surgical approaches like less invasive or delayed surgery in combination with an intensive imaging follow-up.

The main objective of a PET-based predictive model is the actual prediction of the pathological treatment response for patients not included in the patient group on which the model is based. However, so far, none of the presented PET-based response predictive models was yet validated with a secondary patient group. Because for further development and clinical usefulness of PET-based response predictive models a proper validation with a secondary group is required, this study was undertaken to develop a PET-based prediction model to differentiate pathological responders from nonresponders. The predictive strength of the presented predictive model was validated in a second patient group, treated, and imaged identical to the patients on which the predictive model was based.

\section{METHODS AND MATERIALS}

\section{Patient Characteristics}

Fifty-one patients diagnosed with locally advanced rectal cancer were included in this study, from which the clinical TN staging was evaluated on a pretreatment magnetic resonance scan (Table 1). All patients were preoperatively treated with radiotherapy (28 fractions of $1.8 \mathrm{~Gy}, 5$ fractions/week) and concomitant chemotherapy (capecitabine $825 \mathrm{mg} / \mathrm{m}^{2}$ twice daily, 7 days per week), followed by a total mesorectal excision approximately 3 months after the start of preoperative treatment (Fig. 1). Radiotherapy treatment was delivered by four beams, anteroposterior, posteroanterior, and left and right lateral, each with an energy of $10 \mathrm{MV}$. For each patient, a three-dimensional (3D) conformal plan was made according to the International Commission on Radiation Units and Measurements specifications. As a part of the study, all patients underwent fluorodeoxyglucose (FDG) PET-CT imaging both before the start of CRT and at the end of the second week of treatment (Fig. 1). According to the Dutch law, the Medical Ethics Committee approved the trial. All patients gave written informed consent before entering the study.

\section{PET-CT imaging and processing}

All PET-CT scans were performed using a dedicated Siemens Biograph 40 TruePoint PET-CT simulator (Siemens Medical, Erlangen, Germany) with an axial field of view of $16.2 \mathrm{~cm}$, slice thickness of $3 \mathrm{~mm}$, and a pixel spacing of $5.3456 \mathrm{~mm}$ in both directions. The scanner is equipped with ultrafast detector electronics (Pico3D) and has a spatial resolution of approximately 6-mm full-width-at-half-maximum. PET imaging was performed in $3 \mathrm{D}$, requiring a proper scatter correction. CT-based attenuation and decay correction was performed. PET images were reconstructed from the acquired list-mode data using Fourier-rebinning and ordered-subset-expectation-maximization-reconstruction (OSEM 2D) with four iterations and eight subsets. After a fasting period of at least $6 \mathrm{~h}$, FDG was injected intravenously, with the activity normalized for the weight of the patient (weight $[\mathrm{kg}] * 4+20$ ) $[\mathrm{MBq}])$. After an uptake period of $60 \mathrm{~min}$, PET acquisition was started with the patient positioned equal to the radiotherapy treatment position using a movable laser alignment system.

Table 1. Overview of the clinical staging (cTNM), the tumor regression grade (TRG), and the response index (RI) of SUV $\mathrm{max}_{\text {after } 2}$ weeks of preoperative chemoradiotherapy

\begin{tabular}{|c|c|c|c|c|c|c|c|}
\hline Patient no. & cTNM & TRG & RI SUV $_{\max }(\%)$ & Patient no. & cTNM & TRG & $\mathrm{RI} \mathrm{SUV}_{\max }(\%)$ \\
\hline 1 & T2N1M0 & 1 & 51.9 & 1 & T4N1M0 & 3 & 47.6 \\
\hline 2 & T3N2M0 & 3 & 41.7 & 2 & T3N1M0 & 3 & -9.2 \\
\hline 3 & T3N2M0 & 2 & 69.4 & 3 & T3N0M0 & 1 & 62.5 \\
\hline 4 & T4N2M0 & 2 & 38.9 & 4 & T4N1M0 & 4 & 16.9 \\
\hline 5 & T3N1M0 & 2 & 64.8 & 5 & T3N2M0 & 1 & 69.1 \\
\hline 6 & T3N2M0 & 3 & 31.5 & 6 & T3N0M0 & 4 & -19.9 \\
\hline 7 & T3N1M0 & 3 & -11.8 & 7 & T3N2M0 & 4 & 2.9 \\
\hline 8 & T3N2M0 & 3 & 47.6 & 8 & T2N1M0 & 2 & 55.9 \\
\hline 9 & T3N2M0 & 4 & 14.4 & 9 & T3N2M0 & 4 & 10.6 \\
\hline 10 & T3N1M0 & 1 & 70.4 & 10 & T3N1M0 & 3 & 54.4 \\
\hline 11 & T3N2M0 & 4 & 28.8 & 11 & T3N1M0 & 1 & 45.3 \\
\hline 12 & T3N1M0 & 3 & 40.8 & 12 & T3N2M0 & 3 & 40.0 \\
\hline 13 & T3N0M0 & 3 & 4.1 & 13 & T3N1M0 & 4 & 15.0 \\
\hline 14 & T3N2M0 & 3 & 35.9 & 14 & T3N2M0 & 4 & 45.1 \\
\hline 15 & T3N2M0 & 3 & 33.6 & 15 & T2NOM0 & 3 & 1.2 \\
\hline 16 & T3N2M0 & 4 & 28.6 & 16 & T3N2M0 & 2 & 63.2 \\
\hline 17 & T3N2M0 & 1 & 54.6 & 17 & T3N0M0 & 3 & 37.7 \\
\hline 18 & T3N2M0 & 2 & 45.5 & 18 & T3N0M0 & 3 & 44.0 \\
\hline 19 & T3N0M0 & 4 & 5.2 & 19 & T3N1M0 & 1 & 53.1 \\
\hline 20 & T3N2M1 & 3 & -8.2 & 20 & T4N0M0 & 3 & 40.3 \\
\hline 21 & T4N1M0 & 4 & -15.7 & & & & \\
\hline 22 & T3N0M0 & 2 & 48.6 & & & & \\
\hline 23 & T3NOMO & 1 & 68.4 & & & & \\
\hline 24 & T3N2M0 & 2 & 45.6 & & & & \\
\hline 25 & T3N2M0 & 2 & 46.7 & & & & \\
\hline 26 & T3N1M0 & 4 & -7.1 & & & & \\
\hline
\end{tabular}




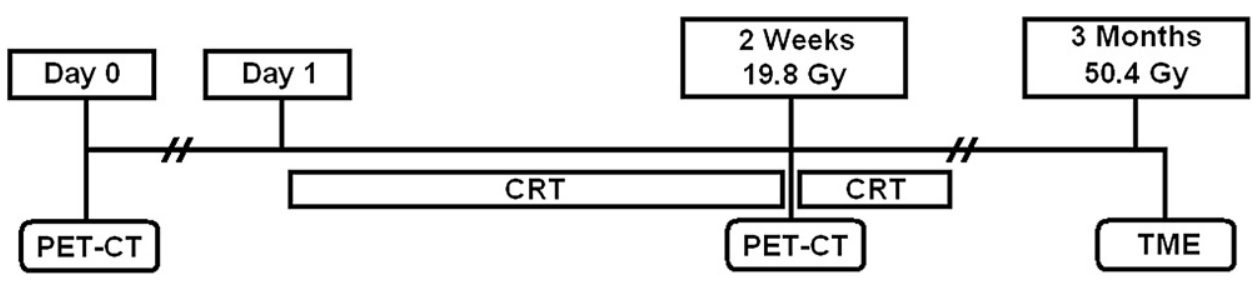

Fig. 1. Study scheme for the assessment of early metabolic response during pre-operative treatment with chemoradiotherapy (CRT). All included patients underwent fluorodeoxyglucose (FDG) positron emission tomography (PET) computed tomography (CT) imaging at two time points: prior to the start of treatment and after two weeks of treatment.

Additionally, all PET data were normalized for the blood glucose level measured shortly before FDG administration (15).

\section{PET analysis}

For each PET scan, the tumor was automatically delineated using SUV thresholding with the threshold (percentage of SUV $\mathrm{max}_{\max }$ within the tumor) depending on the tumor-to-background signal ratio with the gluteus muscle selected as relevant background $(16,17)$. Dedicated software (TrueD VC60, Siemens Medical, Erlangen, Germany) was used to calculate the maximum FDG uptake $\left(\mathrm{SUV}_{\max }\right)$ within the tumor. Subsequently, a response index, indicating the percentage reduction relative to the pre-treatment measured value, was calculated.

\section{Pathological tumor response}

For each tumor, the pathological treatment response was evaluated by determination of the tumor regression grade (TRG) as proposed by Mandard (18). All tumors were retrospectively classified by an experienced pathologist (R.R.), who was blinded for the PET data, as follows: TRG1, complete tumor response; TRG2, residual cancer cells scattered through fibrosis; TRG3, an increased number of residual cancer cells, with predominant fibrosis; TRG4, residual cancer outgrowing fibrosis; TRG5, no regressive changes within the tumor. Based on the TRGs, the patients were grouped into pathological responders (TRG1, 2) and nonresponders (TRG 3-5).

\section{Response prediction and validation}

For 30 of the included patients, the metabolic and pathological treatment responses were correlated using ROC curve analysis. From the ROC curve, a cutoff value for the percent reduction of $\mathrm{SUV}_{\max }$ within the tumor after 2 weeks of chemoradiotherapy (CRT) treatment was selected to differentiate pathological responders from non-responders. When selecting this cutoff value, a high specificity was preferred over a high sensitivity to avoid pathological nonresponders from being false positively predicted as pathological responders, resulting in possible undertreatment of pathological nonresponding patients. Next, the applicability of the selected cutoff value was validated for new patients $(n=21)$, imaged and treated under identical conditions as the patients on which the predictive model was based.

\section{Statistical Analysis}

Statistical analyses were performed using SPSS (version 15.0; SPSS Inc., Chicago, IL).

Comparisons of related measurements were performed using a Wilcoxon signed-rank test and ROC analysis was performed to evaluate the optimal cutoff value of $\mathrm{SUV}_{\max }$ reduction to differentiate pathological responders from nonresponders.

\section{RESULTS}

\section{Peritumoral inflammatory responses}

From the first patient group $(n=30), 4$ patients presented with a peritumoral inflammatory response, visually observed from the PET scan performed at the end of the second week of treatment. Also for the second patient group ( $n=21)$, used for validation of the predictive model, 1 patient presented with a peritumoral inflammatory response. Because inflammatory cells are known to avidly consume glucose, all patients with a peritumoral inflammatory response were excluded from further analysis to prevent an underestimation of the metabolic treatment response of the tumor. When delineating the tumor using automatic SUV thresholding, an increase of the PET-positive tissue volume was found after 2 weeks of CRT treatment for the previously mentioned patients (Fig. 2). The increase of the PET-positive tissue volume is a clear indication of a peritumoral inflammatory response, since an increase of the volume of the malignancy is not to be expected during preoperative CRT treatment. Also, for these patients, a more diffuse FDG uptake was observed after 2 weeks of treatment with a decreased tumor-to-background signal ratio resulting in a less clear PET-based distinction between malignant and nonmalignant tissue (Fig. 2). All visually observed peritumoral inflammatory responses after 2 weeks of treatment were confirmed after pathological examination of the resected specimen.

\section{Response prediction}

For the first patient group, an average reduction of SUVmax within the tumor of $33.6 \pm 25.8 \%(p<0.001)$ was observed after 2 weeks of CRT (Fig. 3, Table 1). The $\mathrm{SUV}_{\text {max }}$ reduction within the tumor was correlated with the pathological response by ROC curve analysis, resulting in an area under the curve of 0.98 (Table 2). From the resulting ROC curve, a cutoff value of $48 \% \mathrm{SUV}_{\max }$ reduction was selected to differentiate pathological responders from nonresponders, resulting in a specificity of $100 \%$ to prevent pathological nonresponders from being false positively predicted as pathological responder (Fig. 4). However, for this cutoff value, a sensitivity of $64 \%$ was found, with 4 pathological responding patients to be false negatively predicted as pathological nonresponding (Fig. 4). 


\section{Pre-Treatment Two Weeks}

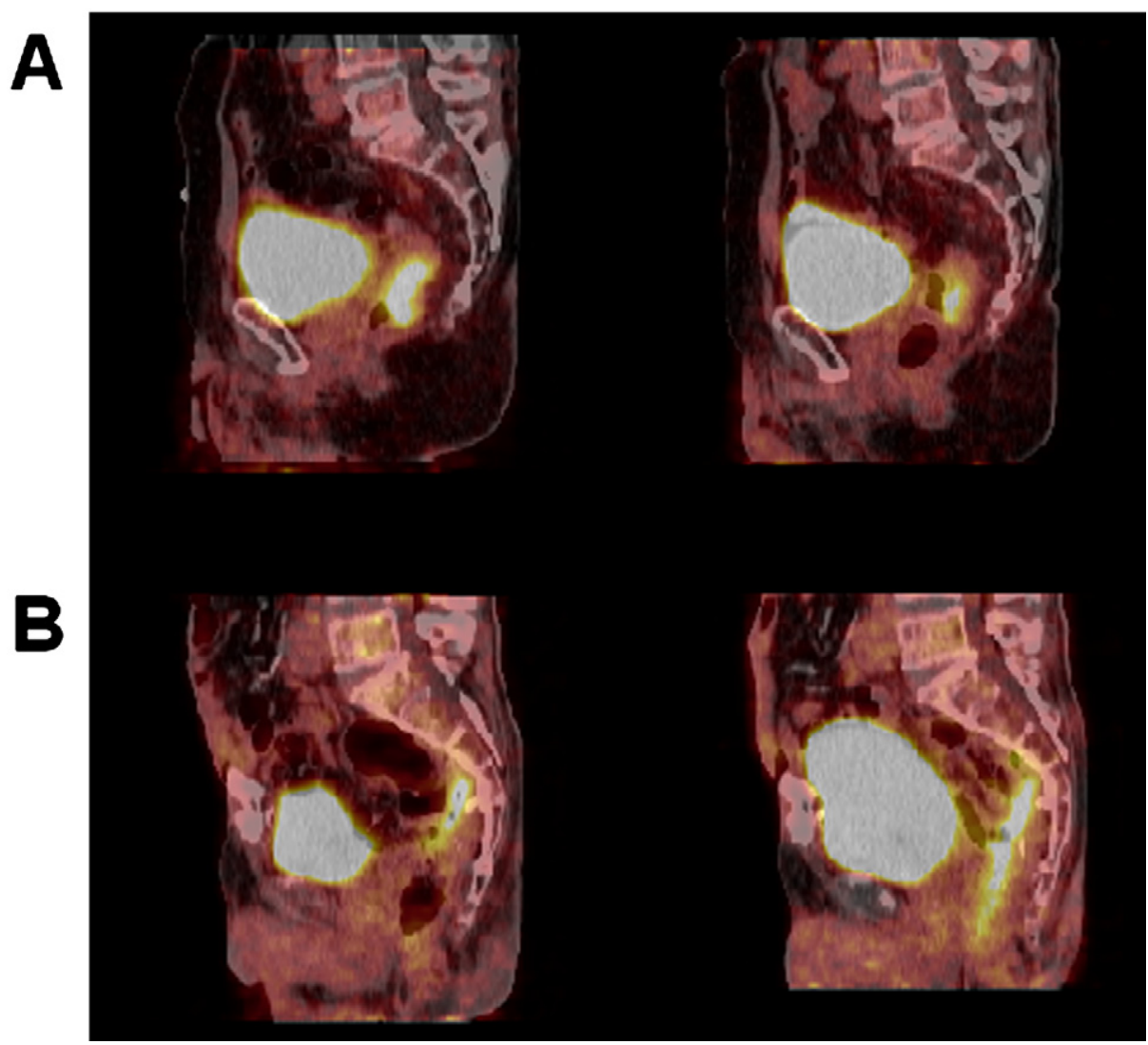

Fig. 2. Fluorodeoxyglucose (FDG) positron emission tomography (PET) computed tomography (CT) images at both PET-CT imaging time points for respectively a representative patient (A) and a patient presenting with a pathological reported peritumoral inflammatory response (B).

\section{Validation}

Also for the second patient group, a significant reduction of $\mathrm{SUV}_{\max }$ within the tumor $(32.3 \pm 27.0 \%, p=0.001)$ was found after 2 weeks of CRT (Fig. 3, Table 1). When applying

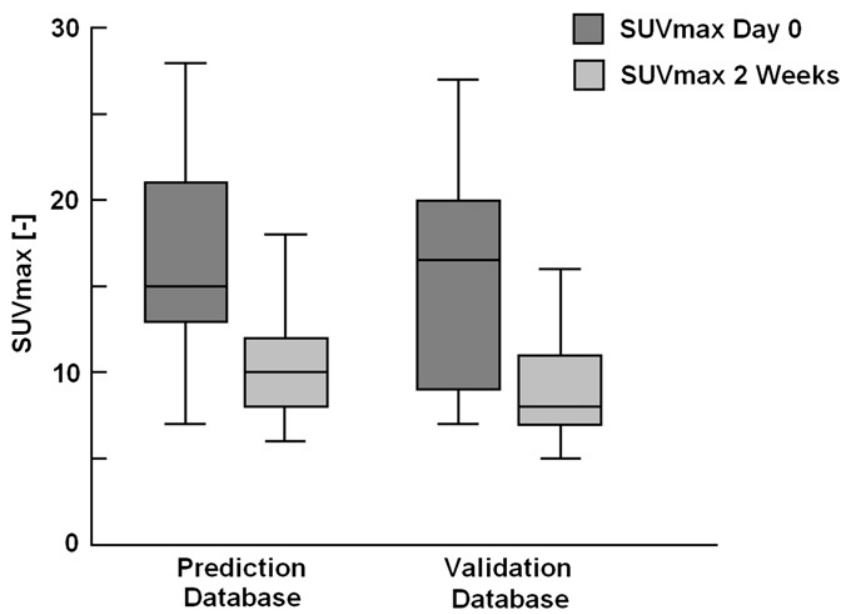

Fig. 3. Boxplots of maximum standardized uptake value $\left(\mathrm{SUV}_{\max }\right)$ within the tumor at both positron emission tomography (PET) computed tomography (CT) time points for both patient groups, with the dark and light gray boxes presenting, respectively, the pretreatment $\mathrm{SUV}_{\max }$ within the tumor and the $\mathrm{SUV}_{\max }$ after 2 weeks of chemoradiotherapy. the ROC curve based cutoff value of $48 \%$ to differentiate pathological responders from nonresponders, a specificity and sensitivity of, respectively, $93 \%$ and $83 \%$ was found, with only one of the pathological nonresponding patients (TRG3) being predicted false positively as pathological responding, whereas one pathological responder (TRG1) was predicted false negatively as being a pathological nonresponder (Fig. 4).

\section{DISCUSSION}

Response predictive models based on changes of the metabolic activity of the tumor, assessed with repeated FDG-PET-CT imaging, were presented to result in accurate predictions of the pathological treatment response (1-14). However, proper validation of published PET-based response predictive models has not yet been performed. This is the first study performing a validation of a PETbased response prediction model using a SUV cutoff value to differentiate pathological responders from nonresponders. Validation of such response predictive models is required to ensure whether the presented model is applicable on patients who are not included in the patient group on which the model is based. When using a PET-based response prediction model for the differentiation of pathological responders 
Table 2. Overview of average metabolic response (RI $\left.\mathrm{SUV}_{\max }\right)$ as assessed with fluorodeoxyglucose (FDG) positron emission tomography (PET) imaging, relative to the tumor regression grade (TRG)

\begin{tabular}{ll}
\hline & \multicolumn{1}{c}{ RI SUV $_{\max }$} \\
\hline TRG 1 & $59.4 \pm 9.4 \%$; range, $45.3-70.4 \%$ \\
TRG 2 & $53.2 \pm 10.5 \%$; range, $38.9-69.4 \%$ \\
TRG 3 & $26.7 \pm 22.9 \%$; range, $-11.8-54.4 \%$ \\
TRG 4 & $13.0 \pm 20.4 \%$; range, $-19.9-45.1 \%$ \\
TRG 1-2 & $56.1 \pm 10.2 \%$; range, $38.9-70.4 \%$ \\
TRG 3-5 & $20.5 \pm 22.5 \%$; range, $-19.9-54.4 \%$ \\
\hline
\end{tabular}

and nonresponders, the cutoff value (percent reduction of the FDG uptake within the tumor) used to differentiate responders from nonresponders should be chosen in such a way that as less nonresponding patients as possible are predicted false positively as pathological responding (12). This, to avoid undertreatment of false positively predicted pathological nonresponders when performing modifications of the treatment protocol based on the predicted treatment response. The selected ROC curve based cutoff value of $48 \% \mathrm{SUV}_{\max }$ reduction at the end of the second week of preoperative CRT (sensitivity 64\%, specificity 100\%) was applied on a second patient group, resulting in a sensitivity and specificity of respectively $83 \%$ and $93 \%$, with one pathological nonresponder being predicted false positively as pathological responding. From these results, it was concluded that a PET-based predictive model using a cutoff value (percent reduction of $\mathrm{SUV}_{\max }$ within the tumor) can be used to accurately predict the pathological treatment response for patients not included in the patient group on which the predictive model is based.

For this study, we defined patients with a TRG of 1 or 2 according to the Mandard criteria as being pathological responders and patients with a TRG 3-5 as pathological nonresponders. Earlier published literature proved patients with TRG1-2 to have a better prognosis compared to patients with TRG3-5 $(19,20)$. Patients presenting with a TRG1 or 2 were proven to have less chance on local failure, whereas they have an improved chance on metastasis- and disease-free survival as well as overall survival (20). Also, an extended time interval between preoperative CRT treatment and surgery has been presented to result in more pronounced tumor regression and downstaging, whereas a shorter time interval may interrupt ongoing of tumor necrosis (21-23). We believe that a PET-based response predictive model as presented in this manuscript could in the near future be helpful to identify those TRG1-2 patients to improve the tumor response by including these patients in a boost trial and/or apply an extended time interval between RT and surgery.

For some of the patients included in this study, a peritumoral inflammatory response was visually observed from the PET images acquired after the second week of CRT. As inflammatory cells are known to avidly consume glucose (analogs), peritumoral inflammatory responses can lead to an underestimation of the metabolic response of the tumor, ultimately resulting in false-negative predictions of pathological responders $(10,12,24)$. Patients presenting with a (visually observed) peritumoral inflammatory response should not be included in the patient group on which a PET-based response predictive model is based and such PET-based response predictive model should not be applied for patient with a peritumoral inflammatory response.

Importantly, when predicting the pathological treatment response based on sequential PET data, standardization of the used PET imaging protocol concerning the PET image reconstruction algorithm, injected FDG activities and uptake periods, SUV calculation method, blood glucose level measurements and correction of the PET data for the blood glucose level is required $(11,16,25-28)$.

In conclusion, this is the first validation of a PET-based model for the prediction of the pathological treatment response. The presented results prove that an accurate prediction of the pathological treatment response based on the reduction of $\mathrm{SUV}_{\max }$ is possible already after 2 weeks of CRT treatment for patients treated and imaged identical to the patients on which the response predictive model is based.
Prediction Database

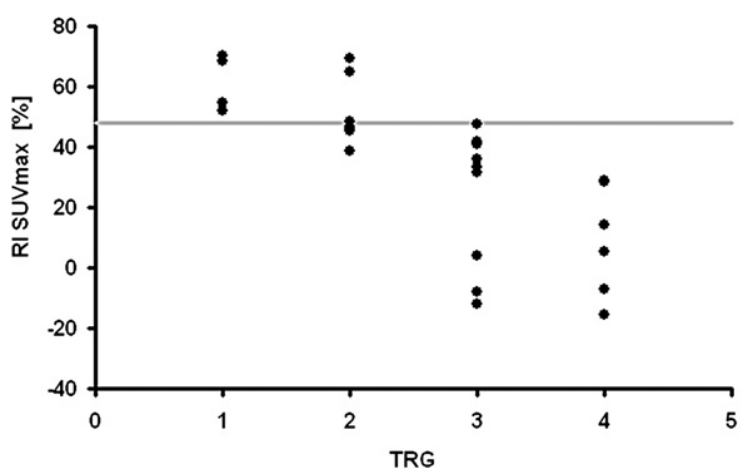

Validation Database

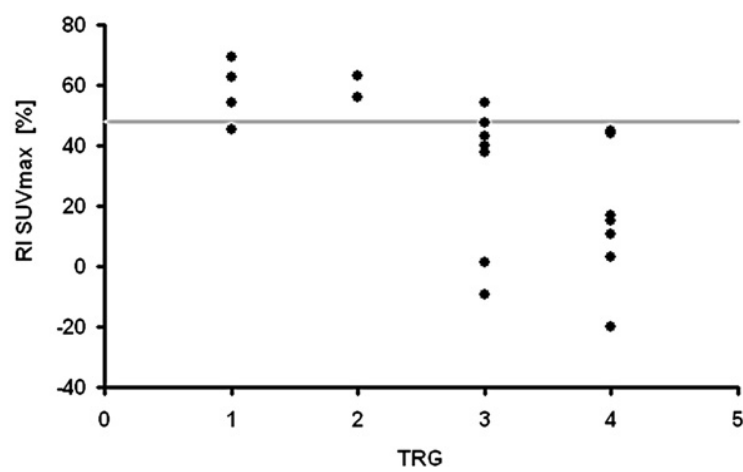

Fig. 4. Response indices (RI) of maximum standardized uptake value $\left(\mathrm{SUV}_{\max }\right)$ after 2 weeks of preoperative chemoradiotherapy relative to the tumor regression grade (TRG) for both the prediction (left) and validation (right) database. The gray horizontal line indicates the receiver operating characteristic curve based cutoff value of $48 \% \mathrm{SUV}_{\text {max }}$ reduction for the differentiation of pathological responders from nonresponders. 


\section{REFERENCES}

1. Capirci C, Rampin L, Erba PA, et al. Sequential FDG-PET/CT reliably predicts response of locally advanced rectal cancer to neo-adjuvant chemo-radiation therapy. Eur J Nucl Med Mol Imaging 2007;34:1583-1593.

2. Capirci C, Rubello D, Chierichetti F, et al. Long-term prognostic value of $18 \mathrm{~F}-\mathrm{FDG}$ PET in patients with locally advanced rectal cancer previously treated with neoadjuvant radiochemotherapy. AJR Am J Roentgenol 2006;187:W202-208.

3. Vliegen RF, Beets-Tan RG, Vanhauten B, et al. Can an FDGPET/CT predict tumor clearance of the mesorectal fascia after preoperative chemoradiation of locally advanced rectal cancer? Strahlenther Onkol 2008;184:457-464.

4. Kalff V, Duong C, Drummond EG, et al. Findings on 18F-FDG PET scans after neoadjuvant chemoradiation provides prognostic stratification in patients with locally advanced rectal carcinoma subsequently treated by radical surgery. $\mathrm{J} \mathrm{Nucl} \mathrm{Med}$ 2006;47:14-22.

5. Amthauer H, Denecke T, Rau B, et al. Response prediction by FDG-PET after neoadjuvant radiochemotherapy and combined regional hyperthermia of rectal cancer: Correlation with endorectal ultrasound and histopathology. Eur J Nucl Med Mol Imaging 2004;31:811-819.

6. Denecke T, Rau B, Hoffmann KT, et al. Comparison of CT, MRI and FDG-PET in response prediction of patients with locally advanced rectal cancer after multimodal preoperative therapy: Is there a benefit in using functional imaging? Eur Radiol 2005; $15: 1658-1666$.

7. Guillem JG, Moore HG, Akhurst T, et al. Sequential preoperative fluorodeoxyglucose-positron emission tomography assessment of response to preoperative chemoradiation: A means for determining long-term outcomes of rectal cancer. J Am Coll Surg 2004;199:1-7.

8. Melton GB, Lavely WC, Jacene HA, et al. Efficacy of preoperative combined 18-fluorodeoxyglucose positron emission tomography and computed tomography for assessing primary rectal cancer response to neoadjuvant therapy. J Gastrointest Surg 2007;11:961-969; discussion 969.

9. Cascini GL, Avallone A, Delrio P, et al. 18F-FDG PET is an early predictor of pathologic tumor response to preoperative radiochemotherapy in locally advanced rectal cancer. $J$ Nucl Med 2006;47:1241-1248.

10. Rosenberg R, Herrmann K, Gertler R, et al. The predictive value of metabolic response to preoperative radiochemotherapy in locally advanced rectal cancer measured by PET/CT. Int J Colorectal Dis 2009;24:191-200.

11. Hindie E, Hennequin C, Moretti JL. Predicting response to chemoradiotherapy in rectal and oesophageal cancer with $18 \mathrm{~F}$ FDG: Prognostic value and possible role in patient management. Eur J Nucl Med Mol Imaging 2007;34:1576-1582.

12. Janssen MH, Ollers MC, Riedl RG, et al. Accurate prediction of pathological rectal tumor response after two weeks of preoperative radiochemotherapy using (18)F-fluorodeoxyglucose-positron emission tomography-computed tomography imaging. Int J Radiat Oncol Biol Phys 2010;77:392-399.

13. Young H, Baum R, Cremerius U, et al. Measurement of clinical and subclinical tumour response using [18F]-fluorodeoxyglucose and positron emission tomography: Review and 1999 EORTC rec- ommendations. European Organization for Research and Treatment of Cancer (EORTC) PET Study Group. Eur J Cancer 2010;95:203-208.

14. de Geus-Oei LF, Vriens D, van Laarhoven HW, et al. Monitoring and predicting response to therapy with 18 F-FDG PET in colorectal cancer: A systematic review. J Nucl Med 2009; 50(Suppl 1):43S-54S.

15. Beaulieu S, Kinahan P, Tseng J, et al. SUV varies with time after injection in (18)F-FDG PET of breast cancer: Characterization and method to adjust for time differences. $\mathrm{J} \mathrm{Nucl} \mathrm{Med}$ 2003;44:1044-1050.

16. Ollers M, Bosmans G, van Baardwijk A, et al. The integration of PET-CT scans from different hospitals into radiotherapy treatment planning. Radiother Oncol 2008;87: 142-146.

17. Daisne JF, Sibomana M, Bol A, et al. Tri-dimensional automatic segmentation of PET volumes based on measured source-to-background ratios: Influence of reconstruction algorithms. Radiother Oncol 2003;69:247-250.

18. Mandard AM, Dalibard F, Mandard JC, et al. Pathologic assessment of tumor regression after preoperative chemoradiotherapy of esophageal carcinoma. Clinicopathologic correlations. Cancer 1994;73:2680-2686.

19. Rodel C, Martus P, Papadoupolos T, et al. Prognostic significance of tumor regression after preoperative chemoradiotherapy for rectal cancer. J Clin Oncol 2005;23:8688-8696.

20. Vecchio FM, Valentini V, Minsky BD, et al. The relationship of pathologic tumor regression grade (TRG) and outcomes after preoperative therapy in rectal cancer. Int J Radiat Oncol Biol Phys 2005;62:752-760.

21. Veenhof AA, Bloemena E, Engel AF, et al. The relationship of histological tumor regression grade (TRG) and two different time intervals to surgery following radiation therapy for locally advanced rectal cancer. Int J Colorectal Dis 2009;24:10911096.

22. Habr-Gama A, Perez RO, Proscurshim I, et al. Interval between surgery and neoadjuvant chemoradiation therapy for distal rectal cancer: Does delayed surgery have an impact on outcome? Int J Radiat Oncol Biol Phys 2008;71:1181-1188.

23. Dolinsky CM, Mahmoud NN, Mick R, et al. Effect of time interval between surgery and preoperative chemoradiotherapy with 5-fluorouracil or 5-fluorouracil and oxaliplatin on outcomes in rectal cancer. J Surg Oncol 2007;96:207-212.

24. Kao PF, Chou YH, Lai CW. Diffuse FDG uptake in acute prostatitis. Clin Nucl Med 2008;33:308-310.

25. Keyes JW Jr. SUV: Standard uptake or silly useless value? J Nucl Med 1995;36:1836-1839.

26. Hamberg LM, Hunter GJ, Alpert NM, et al. The dose uptake ratio as an index of glucose metabolism: Useful parameter or oversimplification? J Nucl Med 1994;35:1308-1312.

27. Boellaard R, O'Doherty MJ, Weber WA, et al. FDG PET and PET/CT: EANM procedure guidelines for tumour PET imaging: version 1.0. Eur J Nucl Med Mol Imaging 2009.

28. Janssen MH, Ollers MC, Stiphout RG, et al. Blood glucose level normalization and accurate timing improves the accuracy of PET-based treatment response predictions in rectal cancer. Radiother Oncol. 